\title{
COMPARATIVE EVALUATION OF APOPTOSIS INDUCED CHANGES IN THYMOCYTES OF SPF CHICKS CO-INFECTED WITH CHICKEN INFECTIOUS ANAEMIA VIRUS (CIAV) AND MAREK'S DISEASE VIRUS (MDV)
}

\author{
Shyma K Latheef ${ }^{1}$, Kuldeep Dhama ${ }^{1 *}$, Hari Abdul Samad ${ }^{2}$, Swathi Sachan ${ }^{3}$, Sruthi $\mathrm{S}^{1}$, \\ Asok Kumar M $^{1}$, Palanivelu M $^{1}$, M R Reddy ${ }^{1}$, Yashpal Singh Malik ${ }^{4}$
}

${ }^{1}$ Division of Pathology, ICAR-Indian Veterinary Research Institute, Izatnagar, Bareilly, India
2 Division of Physiology \& Climatology, ICAR-Indian Veterinary Research Institute, Izatnagar, Bareilly, India
${ }^{3}$ Immunology section, ICAR-Indian Veterinary Research Institute, Izatnagar, Bareilly, India
${ }^{4}$ Division of Biological Standardization, ICAR-Indian Veterinary Research Institute, Izatnagar, Bareilly, India.

Received - April 14, 2019; Revision - May 02, 2019; Accepted - June 10, 2019

Available Online - August 05, 2019

DOI: http://dx.doi.org/10.18006/2019.7(4).418.422

\author{
KEYWORDS \\ Chicken infectious anaemia \\ virus \\ Marek's disease virus \\ Co-infection \\ Apoptosis \\ Thymocytes
}

\begin{abstract}
Chicken infectious anaemia (CIA) and marek's disease (MD) are highly prevalent immunosuppressive viral infections in India and so natural co-infection is also likely to occur. The present study evaluated the extend of apoptosis induced in the thymocytes of SPF chicks challenged with CIAV and MDV both alone and in combination. Seventy two (72) SPF chicks were randomly allocated into 4 groups viz., CIAV (challenged with CIAV on day1), MD (challenged with vMDV on day14), CIAV + MD (challenged with CIAV on day1 and vMDV on day14) and CONTROL (without virus challenge). Three birds from each group were sacrificed on day14, 28 and 42, followed by collection of thymus and thymocytes were separated and suspended in PBS as single cell suspension. Further treatment of cells to release caspase 3 and its colorimetric evaluation were done using caspACE assay kit (Promega). Results of present study indicated a significantly higher $(\mathrm{p}<0.05)$ level of caspase 3 released in CIAV and CIAV + MD groups from day 14 onwards, reached peak on day 28 but by day 42 CIAV alone group showed a decline while in co-infected group the level remained significantly higher $(\mathrm{p}<0.05)$. So results of this study point to a greater extend of apoptosis in co-infected group, aggravating the immunosuppression.
\end{abstract}

* Corresponding author

E-mail: shyma05vet@gmail.com (Shyma k latheef)

Peer review under responsibility of Journal of Experimental Biology and Agricultural Sciences.

Production and Hosting by Horizon Publisher India [HPI] (http://www.horizonpublisherindia.in/).

All rights reserved.
All the articles published by Journal of Experimental Biology and Agricultural Sciences are licensed under a Creative Commons Attribution-NonCommercial 4.0 International License Based on a work at www.jebas.org.

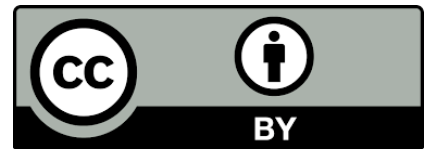




\section{Introduction}

Co-infections with different etiological agents are much frequent in Indian poultry industry, among which infections associated with immunosuppressive pathogens inflicts wide spread impact on the economy (Li et al., 2016; Zhang et al., 2017). Since global requirement for poultry products is increasing, poultry industry is forced to enforce intensive production facilities which ultimately predisposes to stress and immunosuppression (Padhy et al., 2015). This necessitates wider/broader assessments and diagnosis regarding the prevalence of immunosuppression in chicken caused by both noninfectious and infectious causes (Dhama et al., 2008; Wani et al., 2015). Immunosuppressive infections predispose the birds to vaccine failure, loss of natural immunity, growth retardation, low feed conversion efficiency and adversely affects the breeding policies and national disease control measures (Bhatt et al., 2011). Both Chicken Infectious Anaemia (CIA) and Marek's Disease (MD) are highly prevalent viral immunosuppressive diseases of Indian poultry (Gupta \& Deka, 2016; Ganar et al., 2017).So it is highly warranted to have clear cut idea over the extend of pathogenesis like apoptosis induced in the target tissues of susceptible birds which are coinfected with CIAV and MDV so as to rethink the vaccination and management practices to curtail the economic losses.

The genetically controlled process of apoptosis or programmed cell death is sequel to several infectious and non infectious pathological events. Though it is necessary to have balanced cellular apoptosis for normal physiology, uncontrolled or unregulated decrease in apoptosis of cells leads to tumour conditions while increase will end in fatal outcomes (Elmore, 2007). Primarily there exists an intrinsic and an extrinsic pathway, the former being initiated with caspase8 activation while the latter depends on activation of caspase9 (Cohen, 1997). Both the pathways are finally terminated with the executioner factor caspase3 for final apoptotic events (Kvansakul, 2017). It is the apoptosis induced by CIAV in the lymphoblastoid cells like thymocytes, which is the main pathological mechanism exerted in chicken and clinical manifestations and secondary complications are attributed to this mechanism only (Crowley et al., 2011). Hence the present study has been executed to elucidate the extend of apoptosis in thymocytes in chicks coinfectd with CIAV and MDV for the better understanding of the coinfection pathology.

\section{Materials and Methods}

\subsection{Experimental birds}

The present study was conducted in total 72 specific pathogen free (SPF) chicks, hatched out aseptically in the hatchery unit of ICAR-Central Avian Research Institute, Izatnagar, from SPF eggs procured from the M/S Venkateshwara Hatcheries Group Limited (VHL), Pune, Maharashtra, India.

\subsection{Challenge viruses}

Indian field isolates of CIAV strain A and virulent MDV maintained in the Avian Diseases sections, ICAR-IVRI was used for the study after following standard virus titration methods for each virus.

\subsection{Study site}

Chicks were housed in the experimental sheds of Avian disease section within IVRI campus with proper biosecurity measures for challenge study. Control group was kept separately in the control shed at considerable distance. Birds were provided with adlibitum feed and water after autoclaving.

\subsection{Experimental design}

Chicks were randomly divided into 4 groups (CIAV, MD, CIAV + MD AND CONTROL) with 18 birds per group. CIAV and CIAV + MD groups were challenged with CIA virus at a dose of $50 \mathrm{CID}_{50}$ intramuscularly at day old age as per Kaffashi et al. (2006). MD group was challenged with 1000PFU of MDV intraperitoneally at $14^{\text {th }}$ day of age. Control group was maintained uninfected. For assessing the caspase3 secretion from thymocytes, 3 birds from each group were sacrificed on $14^{\text {th }}, 28^{\text {th }}$ and $42^{\text {nd }}$ days post CIAV infection, from 4 groups, followed by aseptic separation of thymocytes and cells were treated for caspase 3 release and colorimetric estimation using commercial assay kit as per manufactures protocol. For the separation of thymocytes, thymus lobes were collected from sacrificed chicks aseptically and placed in sterile petri dishes. After washing with sterile PBS ( $\mathrm{pH} 7.4$ ), tissue was transferred to another dish, minced into $3-4 \mathrm{~mm}$ pieces with cold PBS and washed to remove RBCs. Again minced for individual thymocytes and centrifuged at $250 \mathrm{~g}$ for 5 minutes, discarded supernatant, cells suspended in $5 \mathrm{ml}$ PBS. Individual cell suspension was filtered through cell strainer, collected in sterile tubes suspended in PBS and cell count was assessed.

Colorimetric estimation was done using caspACE assay kit (Promega, USA) following manufactures protocol. Initially, a standard curve was prepared (Fig. 1) using different known concentrations of paranitoaniline (pNA) plotted against corresponding absorbance at $405 \mathrm{~nm}$ for quantifying the caspase 3 released from the cells. Thymocytes collected from each bird was centrifuged at 2000rpm for5 minutes to obtain cell pellet, suspended with lysis buffer (provided in the kit) and added onto each well of 24-well culture plate (@ 1 $\times 10^{8}$ cells / ml). Cells were lysed by repeated freeze-thaw, then incubated on ice for 15 minutes, followed by centrifugation at $15,000 \times \mathrm{g}$ for 20 minutes at $4^{\circ} \mathrm{C}$, and collected the supernatant fraction which was used as the enzyme source. The assay was performed in a total volume of 
$100 \mu 1$ in 96-well plates and reaction set up for each well is given in table 1 . Then, $2 \mu 1$ of DEVD-pNA Substrate $(10 \mathrm{mM}$ stock) was added to all wells and incubated at $37^{\circ} \mathrm{C}$ for 4 hours followed by measuring absorbance in the each wells at $405 \mathrm{~nm}$.

Quantitative analysis of caspase3 released by cells in each group was extrapolated from the standard curve (Figure 1). Values were analysed statistically by 2-way repeated measures ANOVA using Graphpad prism software version 7.

\section{Results and Discussion}

The caspase 3 released by thymocytes of chicks in different groups under study is given in table 2 and figure 2. Caspase 3 released is expressed in terms of and proportional to the paranitroaniline (pNA) released from the culture due to the action of the enzyme. Our results showed that the amount of caspase 3 released on $14^{\text {th }}$ day was significantly higher in CIAV and CIAV + MD groups, indicating the apoptosis in thymocytes induced by CIA virus. By $28^{\text {th }}$ day level of apoptosis reached its peak in these two groups while a decline was indicated by $42^{\text {nd }}$ day, but the level was significantly higher in co-infected group than CIAV alone. Caspase3 from MD group remained comparable to that of control group up to $28^{\text {th }}$ day, whereas on $42^{\text {nd }}$ day the level in MD group was significantly elevated than control but remained comparable with that of CIAV and at a significantly lower level with that of co-infected group.

Apoptosis induced by CIAV in the lymphoblastoid cells, thymocytes in particular, is the main pathological mechanism exerted in the host and clinical manifestations and secondary complications are attributed to this mechanism only (Smyth et al., 2006). Previous studies found out that CIAV induce cytopathogenic effects invivo in chicken thymocytes and transformed cells of chicken origin in vitro via apoptosis (Noteborn, 2004; Kucharski et al., 2016). It has been reported that apoptin or VP3 protein of CIAV induces apoptosis by using host cellular components especially of intrinsic / mitochondrial apoptotic pathway and this involve the downstream caspases particularly caspase 3 as the ultimate executioner of apoptosis (Danen-van Oorschot, 1999). Our results also run in accordance with the above reports since a significant increase in the release of caspase 3 could be seen in the initial 4 weeks of CIAV infection. Reduction in apoptosis by day 42 indicates potential restriction over CIAV pathogenesis and apoptin induced apoptosis which can be attributed to the neutralizing antibodies developed by that time (Schat, 2009; Dhama et al., 2011). It has been reported that though MDV exerts lymphoproliferative
Table 1 Reaction set up for caspase colorimetric assay

\begin{tabular}{|l|l|}
\hline Caspace assay buffer & $32 \mu 1$ \\
\hline DMSO & $2 \mu 1$ \\
\hline DTT, $100 \mathrm{mM}$ & $10 \mu 1$ \\
\hline Sample cell extract & $20 \mu 1(25-100 \mu$ g total protein $)$ \\
\hline Deionised water & upto $98 \mu 1$ \\
\hline
\end{tabular}

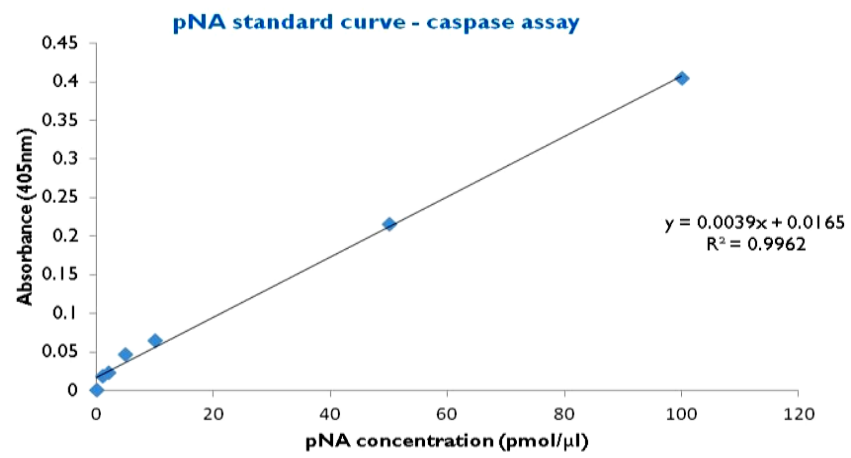

Figure 1 Standard curve generated with various concentrations of pNA and corresponding absorbance at $405 \mathrm{~nm}$ for colorimetric estimation of caspase 3 released by cells.

Table 2 Results showing the release of caspase 3 by thymocytes in different groups

\begin{tabular}{|ccccc|}
\hline \multirow{2}{*}{ DAYS } & \multicolumn{4}{c|}{ EXPERIMENTAL GROUPS } \\
& CONTROL & CIAV & MD & CIAV + MD \\
\hline 14 & $39.20 \pm 7.03^{\mathrm{a}}$ & $379.58 \pm 35.30^{\mathrm{b}}$ & $56.92 \pm 3.83^{\mathrm{a}}$ & $327.95 \pm 33.67^{\mathrm{b}}$ \\
\hline 28 & $46.04 \pm 6.91^{\mathrm{a}}$ & $823.93 \pm 75.78^{\mathrm{b}}$ & $166.67 \pm 31.65^{\mathrm{a}}$ & $753.27 \pm 94.60^{\mathrm{b}}$ \\
\hline 42 & $42.31 \pm 2.96^{\mathrm{a}}$ & $198.62 \pm 43.70^{\mathrm{b}}$ & $214.27 \pm 16.16^{\mathrm{b}}$ & $505.38 \pm 2.91^{\mathrm{c}}$ \\
\hline
\end{tabular}

Value given as mean \pm SEM of picomols of pNA liberated due to caspase 3 from the cells. Values bearing different superscripts differ significantly $(p<0.05)$ between groups within a day.

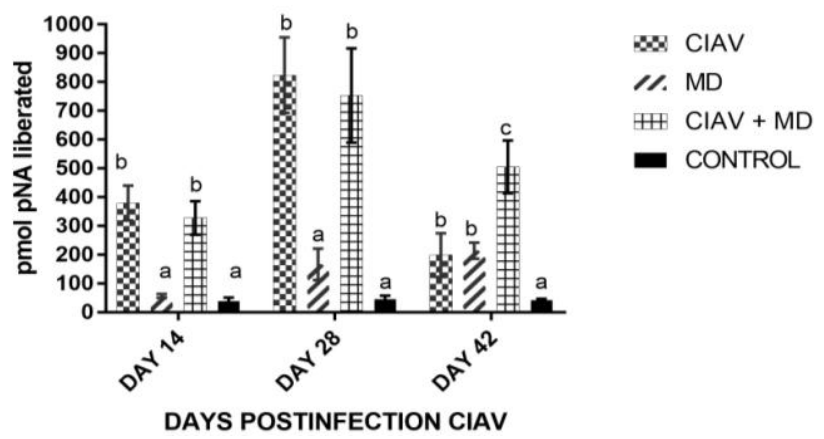

Figure 2 Results showing the release of caspase 3 by thymocytes in different groups expressed as mean \pm SEM of picomols of pNA liberated due to caspase 3 from the cells. Values bearing different superscripts differ significantly $(p<0.05)$ between groups within a day. 
changes in birds (Lee et al., 2000; Gimeno, 2008) an early cytolytic phase of MDV pathogenesis has been reported (Gimeno, 2008; Boodhoo et al., 2016) where it induces substantial apoptosis in immune cells especially B cells. This is evident in the substantial increase in the level of caspase 3 released by MDV infected thymocytes during initial 4 weeks of MDV challenge. Results in CIAV + MD group showed a greater extend of apoptosis in this group at all time points than other two groups. This indicates that the restriction of CIAV induced apoptosis by day 42 (as evidenced in CIAV group) was violated in this group which may be due to decline in protective humoral responses and neutralizing antibody production, since coinfection with MDV specifically lyse the B cells. This indicates an aggravated tissue damage in the combined infection which is fatal and can pave for persistence in infection with sever degree of clinical manifestation at the cost of production loss.

\section{Conclusion}

The study indicates that the extend of apoptosis in chicken thymocytes induced by CIAV in co-infection with MDV is extensive and persisting in comparison with the CIAV alone infection.

\section{Conflict of Interest}

Authors would hereby like to declare that there is no conflict of interests that could possibly arise.

\section{References}

Bhatt P, Shukla SK, Mahendran M, Dhama K, Chawak MM, Kataria JM (2011) Prevalence of Chicken Infectious Anaemia Virus (CIAV) in commercial poultry flocks of Northern India: A Serological Survey. Transboundary and Emerging Diseases 58: 458-460.

Boodhoo N, Gurung A, Sharif S, Behboudi S (2016) Marek's disease in chickens: a review with focus on immunology. Veterinary Research 47:119-137.

Cohen GM (1997) Caspases: the executioners of apoptosis. Biochemical Journal 326: 1-16.

Crowley TM, Haring VR, Moore R (2011) Chicken Anemia Virus: An Understanding of the in-vitro host response over time. Viral Immunology 24: 3-9.

Danen-van Oorschot AA (1999) The effect of Bcl-2 on apoptin in normal cell versus transformed human cells. Leukemia 13:75-77.

Dhama K, Mahendran M, Somavanshi R, Chawak MM (2008) Chicken infectious anaemia virus: An immunosuppressive pathogen of poultry - A review. Indian Journal of Veterinary Pathology 32: 158-167.

Dhama K, Singh SD, Somvanshi R, Kataria JM (2011) Chicken infectious anaemia: (an economically important immunodepressive viral disease of poultry). ICAR-NAE Project Publication, IVRI, Izatnagar, pp: 1-36.

Elmore S (2007) Apoptosis: a review of programmed cell death. Toxicologic Pathology 35:495-516.

Ganar K, Shah M, Kamdi BP, Kurkure NV, Kumar S (2017) Molecular characterization of Chicken Anemia Virus outbreaks in Nagpur province, India from 2012 to 2015. Microbial Pathogenesis 102: 113-119.

Gimeno IM (2008) Marek's disease vaccines: A solution for today but a worry for tomorrow? Vaccine 26S: C31-C41.

Gupta M, Deka D (2016) Sequence analysis of Meq oncogene among Indian isolates of Marek's disease herpesvirus. Meta gene 9: 230-236.

Kaffashi A, Noormohammadi AH, Allott ML, Browning GF (2006) Viral load in 1-day-old and 6-week-old chickens infected with chicken anaemia virus by the intraocular route. Avian Pathology 35: 471-474.

Kucharski TJ, Timothy FN, Sharon DM, Navid-Azarbaijani P, Tavassoli M, Teodoro JG (2016) Activation of the Chicken Anemia Virus apoptin protein by chk1/2 phosphorylation is required for apoptotic activity and efficient viral replication. Journal Virology 90: 9433-9445.

Kvansakul M (2017) Viral Infection and Apoptosis. Viruses 9: 356

Lee LF, Wu P, Sui D, Ren D, Kamil J, Kung HJ (2000) The complete unique long sequence and the overall genomic organization of the GA strain of Marek's disease virus. PNAS 97:6091-6096.

Li Y, Wang Y, Fang L, Fu J, Cui S, Zhao Y, Cui Z, Chang S, Zhao P (2016) Genomic analysis of the Chicken Infectious Anemia Virus in a Specific Pathogen-Free Chicken Population in China. BioMed Research International ID 4275718: 1-5.

Noteborn MHM (2004) Chicken anaemia virus induced apoptosis: underlying molecular mechanisms. Veterinary Microbiology 98: 89-94.

Padhy A, Sahu AR, Sahoo S, Ganguly S (2015) Chicken Infectious Anemia: A review on its potential threat to poultry industry worldwide. World Journal of Biology and Medical Sciences 2: 17-19. 
Schat KA (2009) Chicken infectious anaemia. Current Topics in Microbiology and Immunology 331: 151-183.

Smyth J, Moffett D, Connor T, McNulty M (2006) Chicken anaemia virus inoculated by the oral route causes lymphocyte depletion in the thymus in 3-week-old and 6-week-old chickens. Avian Pathology 35:254-259.

Wani MY, Dhama K, Tiwari R, Barathidasan R, Malik YS, Singh
SD, Singh RK (2015) Immunosuppressive effects of chicken infectious anaemia virus on $\mathrm{T}$ lymphocyte populations using flow cytometry and hematological parameters during experimental subclinical infection in chicks. Advances in Animal and Veterinary Sciences 3: 143-150.

Zhang Y, Cui N, Han N, Wu J, Cui Z, Su S (2017) Depression of vaccinal immunity to Marek's Disease by infection with Chicken Infectious Anemia Virus. Frontiers in Microbiology 8:1863. 